Article

\title{
Participatory Sustainability Approach to Value Capture-Based Urban Rail Financing in India through Deliberated Stakeholder Engagement
}

\author{
Satya Sai Kumar Jillella*, Annie Matan and Peter Newman \\ Curtin University Sustainability Policy (CUSP) Institute, Curtin University, Building 209, Bentley, \\ Perth 6845, WA, Australia; E-Mails: anne.matan@curtin.edu.au (A.M.); \\ p.newman@curtin.edu.au (P.N.) \\ * Author to whom correspondence should be addressed; E-Mail: s.jillella@postgrad.curtin.edu.au; \\ Tel.: +61-892-669-030; Fax: +61-892-669-031.
}

Academic Editor: Marc A. Rosen

Received: 9 December 2014 / Accepted: 27 May 2015 / Published: 24 June 2015

\begin{abstract}
Increasingly, cities around the world are seeking innovative financial mechanisms to build rail transit projects. Land value capture (VC) is a financing mechanism to fund urban rail transit. Often $\mathrm{VC}$ mechanisms are viewed only as a financing tool applied in relation to increased land values from the administration and legislation perspectives, without actively involving the community in the process. The lack of such participation has resulted in the under collection of the true value established. The transit beneficiary community and city tax payers are especially important stakeholders in this process as their willingness to participate is really critical to the overall VC success and transport outcome. This paper introduces a participatory sustainability approach to enable a more deliberated stakeholder engagement intervention across the VC life cycle. A four-step "Participatory Strategic Value Capture (PSVC)" framework is proposed offering step-by-step guidance toward facilitating a meaningful stakeholder dialogue, deliberation, and collaboration around the stated engagement interests. The PSVC framework, applied to the proposed Bangalore sub-urban rail project in India, has demonstrated the importance of stakeholder engagement using deliberated participatory approaches from a win-win perspective.
\end{abstract}


Keywords: value capture; deliberative processes; participatory sustainability; urban land values; rail transit funding; stakeholder engagement

\section{Introduction}

Cities across the globe have recognized rail transit systems as an emergent multi-functional solution to a range of urbanism challenges today [1-3]. However, most of them are struggling to find funds through traditional methods, and are seeking for alternate innovative financing solutions. Indian cities are no exception. Poor urban mobility can negatively impact the fast emerging developing economies, such as India, where cities primarily form the epicenter for such growth. In this context, worldwide, monetization of urban land values through passive and active interventions is gaining attention as an alternate financing mechanism to fund urban rail transit. Cities in North America, Europe, Canada, Australia, New Zealand, and a few cities in Asia and Africa have opted for induced land value capture (VC) mechanisms as an alternate funding to build rail transit systems [4-6]. Land value capture refers to a type of innovative public financing, in which increases in land values generated by a new public infrastructure investment are all or in part "captured" through a land related tax or any other active or passive mechanisms, such as betterment charges, tax increment financing, air rights sale, property development, to pay back such an investment [7]. In other words, VC, in a broader sense, opposes the windfall gains derived out of public infrastructure creation accrued to a privileged few as unearned income, but argues for redistribution of such gains fully or partially to fund public investment and also to compensate social-costs often resulting from these investment negativities [8]. However, the VC concept is still perceived as a work-in-progress with varied success. As evident from these global experiences, this was primarily due to the fact that there is a notional misconception of the VC mechanism as only a financing tool $[9,10]$. The majority of these practices looked at the VC process only from the fiscal policy, administration and legislation perspectives. Often, VC is viewed as a tax tool or technique in the hands of planners, local governments, and investors, to fund infrastructure invested alone. Therefore, many of these practices lack clarity on the redistribution of the "captured" gains beyond recovering the transit investment. Mostly they have overlooked the needed support investments for infrastructure integration and the sustainable community living aspects [11].

In this context, stakeholder engagement has been recognized as a possible effective option to complement the VC process and move beyond being simply another tax tool to offer a powerful enabler for sustainable transit community development goals [9]. Whether as a resident with transportation concerns or as a user of transit, streets, or public spaces, a citizen's opinion is vital in helping define the $\mathrm{VC}$ process from planning to implementation [12]. Both the transit beneficiary community and the city taxpayer community are potential key stakeholders in defining the VC process. Recently, a few cities in India have attempted to tap urban land values as an alternate funding source for urban infrastructure using new financial instruments like impact fees, higher Floor Area Ratio (FAR) sales, auction of public properties, and mostly structured them as a one-time charge collected to partly pay toward public infrastructure required by new developments. The majority of such initiatives have limited the community participation either to information sharing or to consultation approaches 
only [13]. Moreover, the lack of participatory approaches in the $\mathrm{VC}$ process has led to an under-assessment and/or under-collection of the true value established and have been unable to fully explore the true potential of actual value created [11]. Smolka [14] reiterates that citizen or community engagement in service and policy design is not only the right thing to do but will also provide a rich source of ideas to the government. Community and local businesses are especially important external sources of ideas as they form the beneficiary user group and directly feel the impact of the stated public investment and services. The success of $\mathrm{VC}$, thus, depends on community engagement and their willingness to participate in the process. Hence a participatory sustainability approach to the VC process is needed to engage with the stakeholders as partners in the process rather than as mere actors in the process.

Uncertainty remains about how to do VC-based stakeholder engagement, when it should commence, the methods that should be used and which members should be consulted. In practice, stakeholder engagement is not a simple task as many stakeholders are disengaged, especially when certain groups within the population are marginalized [15]. Of late, Deliberative Democracy (DD) techniques seek out how community engagement in decision-making can find broad support from all key stakeholders, especially the general public, for a policy direction [16]. To this end, a participatory route utilizing deliberative methods is regarded as the most effective process that will enable positive outcomes. This is the goal behind the participatory sustainability approach in VC context examined in this paper.

The paper sets out how to do a participatory sustainability approach within a VC context, from planning to implementation stages, using deliberative consultation approaches. It provides a four-step "Participatory Strategic Value Capture (PSVC)" framework, offering step-by-step guidance to interventions along with providing various approaches of undertaking stakeholder participation across the VC life cycle. The PSVC framework proposes a deliberated stakeholder engagement method using various $\mathrm{DD}$ techniques that are relevant in a $\mathrm{VC}$ context to help facilitate a meaningful deliberation to enable the co-creation of an inclusive and context specific VC strategy. This paper describes the application of the PSVC framework in the context of defining VC-based financing for the proposed Bangalore sub-urban rail project using high quality DD techniques. The paper first introduces a participatory sustainability approach within a VC context, proposes the PSVC framework, and then describes its application in Bangalore to examine the benefits of utilizing participatory approaches in defining a VC process. It then assesses whether this PSVC framework has the potential to assist other cities worldwide looking to undertake a $\mathrm{VC}$ process to deliver public transport involving stakeholder engagement.

\section{Background to Participatory Sustainability Approach in a VC Context}

\subsection{Need for Participatory Stakeholder Engagement in a VC Context}

Holmes (2011) [17] (p. 13) states that "engagement is not a single process or set of activities. It is an ongoing process or conversation that builds trust and relationship". The Organization for Economic Cooperation and Development (OECD) [18] (p. 30) classify stakeholder engagement into three forms of engagement: information sharing, consultation, and participation. The first level, "information 
sharing" is basically a one-way communication approach where information is passed from the decision makers to the stakeholders. The second level, "consultation", is where stakeholders are able to feed into parts of the decision-making process, but are not able (or empowered) to ensure that their aspirations were taken into account. The third level, "participation", enables stakeholders to be involved in the decision-making process [18]. The participatory route with deliberative democratic approaches is regarded as a much more influential process to have positive results. This engages randomly selected people from the general public as well as stakeholders so it can create engagement or collaboration or empowerment forms of participation [19]. Many successful community engagement experiences envisage that having the general public and stakeholders engaged at the helm of the policymaking process transforms them as an agent of change and co-creator with a systematic pursuit of sustained collaboration $[14,19]$.

A participatory approach, therefore, demands a major paradigm shift in the thought processes of government agencies and community. Furthermore, engagement processes require stakeholders to acquire specialized skills in order to have a successful collaboration. For example, Holmes (2011) [17] (p. 1) highlighted that government or public agencies may be required to develop new roles as enablers, negotiators, and collaborators, and, at the same time, the community may be required to demonstrate a willingness to be actively engaged in the process (and dedicate time to the process) along with being sufficiently well informed to enable their participation and deliberation to be effective.

Overall, the expected benefits from stakeholder engagement utilizing a participatory sustainability approach within a VC context includes generating good will, removing uncertainty, and enabling community expectations to be at the forefront of decisions, amongst other benefits. Furthermore, it provides an opportunity to receive stakeholder support in the initial stages of the process and participation from the community helps to enable democratically agreed VC fund redistribution strategies. If such agreement happens, it can help to enable the captured value to be re-distributed proportionately to related community support systems, along with the transit investment that was necessary to enable the transit to be built. Primarily, the participatory sustainability approach actively facilitates community and stakeholder involvement in decisions that affect them directly. However, in practice, undertaking stakeholder engagement in a democratic dialogue is essentially a multifaceted and multi-dimensional challenge [20]. The literature on stakeholder engagement emphasizes the need for community engagements to be far reaching, inclusive, balanced, and facilitated through a democratic dialogue [21].

\subsection{Role and Techniques for Deliberated Participatory Stakeholder Engagement in a VC Context}

There is no single tool or technique to influence successful stakeholder engagement, but a combination of several tools are used to enable the desired engagement outcomes. Different people or communities prefer different engagement methods, and some methods work better for some activities than others. The determination of which technique is the right technique is influenced by several factors, namely: set engagement objectives; desired outcomes; type of engagement; stakeholder types; level of engagement; socio-politico-cultural environment; time, cost and skill set available; and the stage of project progress [22]. Whichever method is selected, it is worthwhile to consider access for all people or communities of interest, including hard-to-reach groups. The commonly used techniques 
across different levels of the stakeholder engagement process, as prescribed by the quick method selector of Bolton's Community Engagement and Consultation toolkit, include publicity campaigns, and exhibitions and road shows are common for information-sharing purposes; focus groups, surveys (self completion, telephone, or face to face), citizens panel, advisory committees, feedback and suggestions, website based inputs, public meetings, are popular during stakeholder consultation stage; ward councilor contact or user panel for citizen involvement stages; community needs analysis, citizen juries, and visioning workshops, are advised for the collaboration stage [22].

DD goes beyond these techniques to ensure there are not just stakeholder but randomly selected citizens who can ensure meaningful participation with inclusiveness, deliberation, dialogue, and acceptable consensus [23]. To this end, DD is an established approach that provides a powerful and effective way for communities to collaboratively problem solve and co-create sustainable outcomes together with decision makers and technical experts. Carolyn and Lars (2006) [24] (p. 20) state that DD advances richer forms of public participation that engage citizens in a structured dialogue around focused policy issues, and yields benefits to participants and sponsors that extend beyond the collection of useful information. Carolyn and Lars (2006) [24] (pp. 24-25, 31-32) recommended eight DD techniques to integrate public deliberation into agency decisions, namely; "ChoiceWork Dialogue, Citizens Jury, Consensus Conference, Deliberative Polling, Issue Forums, Study Circles, 21st Century Town Meeting, and Citizen Assemblies". These approaches seek to find "broad support" from all key stakeholders as well as citizens for a policy direction. Similarly, Hartz-Karp (2013) [25] (pp. 45-90) suggests seven DD techniques that are suitable for a participatory sustainability approach to enable interactions, dialogue and ideally deliberation between all stakeholders. The DD techniques recommended as suited to facilitate the VC based stakeholder engagement process are selected from Hartz-Karp (2013) [25] (pp. 111-119) and are detailed below:

(1).Consensus Forum: This is a popular deliberation process in aiding shared understanding and meeting consensus in a complex and difficult decision making situation, where a variety of stakeholders namely, public, private, resident community, and civic societies are involved in decision making. This technique is particularly useful when the participants are greater in number and representing divergent views on more intricate issues, or most argumentative issues as the approach aids the consensus-based decision-making process.

(2).Multi-Criteria Analysis (MCA): The MCA technique is a structured iteration-based deliberation technique, leveraging scientific data and technology to help the decision-making process. This technique is a means of simplifying complex decision-making tasks, which may involve many stakeholders, a diversity of possible outcomes, and many, and sometimes intangible, criteria by which to assess the outcomes. This tool would help to prioritize a set of options identified with appropriate weightages assigned, and rank them based on the pre-set deliberation objective.

(3).World Café: This technique offers a simple, effective, and flexible format for hosting large group dialogue using participatory rounds of shared interactions especially in joint visioning, planning, and designing context, to motivate networked exchanges in smaller group rounds. In this approach, participation is only by invitation, based on the purpose of the meeting. World cafés can be used across a specific issue or multiple issues, where people engage in progressive rounds of conversations ascertaining questions related to a particular issue in each cluster. 
(4).21st Century Town Meeting/Dialogue: This technique is a software enhanced public deliberation forum with near real-time outputs and priorities generated. This technique is more useful to conduct with a large group deliberation, and provides instant feedback. Participants are linked through online networked computers, and engage in informed deliberation in smaller groups through real-time feedback and deliberation to find common themes and priorities on most contentious issues. This primarily seeks substantive feedback on key issues, finding common ground, and to prioritize what is most important toward influencing decision-making.

(5).Open Space Technology: The Open Space Technology meeting is to create time and space for people to engage deeply and creatively around issues of concern to them. Later, an open circle meeting is reconvened, where all participants can give their comments as part of a facilitated process. This is followed with a final plenary session where participants can give comments and, finally, it provides the outcome with a common understanding on defined goals, actions, milestones, and responsibilities with a way forward.

(6).Local Area Forum: This technique is popular to bring together government, industry, and community to determine the optimal use of scant resources through coordinated actions and joint collaboration. It is more representative of the local community and can get greater local ownership of issues. In this method, local community is more involved and empowered to make informed decisions on what the community requires.

(7).Strategic Questioning: This is a powerful problem-solving technique to engage groups in innovative thinking, to develop strategy, to facilitate change, and to gain acceptance to new ideas. Strategic questioning as a tool helps to find creative ways in times of uncertainty, conflict and confusion, and in case of current thinking, appears to be constrained.

The set of DD techniques provide a powerful and effective way for communities to engage and co-create more consensual policy decisions with communities, public sector decision-makers and other "experts". The deployment of appropriate techniques will depend on the engagement objectives, such as understanding stakeholder expectations, assessing levels of participation interest, and other interconnected objectives [26]. Deliberative forms of democratic decision making help increase the level of responsibility that citizens take for their own actions and behaviors. Participation also gives stakeholders an opportunity for social learning by hearing the views of other stakeholders, talking through the range of possible solutions, and comparing the impacts of various alternatives in terms of their collective short-term and long-term interests.

\subsection{Review of Best Practices for Participatory Stakeholder Engagement in a VC Context}

Worldwide, there are many notable public participatory approaches in practice for community engagement in decision-making, which seeks to find broad support from all key stakeholders for a policy direction. This section highlights a few of such best practices that could be applied to the issue of monetization of urban land values for financing urban infrastructure.

In the late 1990s and early 2000, a new form of civic participation model, Community Benefit Agreements (CBAs) became popular in urban redevelopment practice and to claim public subsidies by developers in North America. Musil [27] (p. 829) defines the CBA process as "a developer enters into a private contract, usually with a coalition of community, faith-based, or special interest groups in 
exchange for their support, cooperation, or forbearance regarding the proposed development". More importantly, the developer is interested in such support before approaching agencies for formal approvals and regulatory changes. Typically, CBAs are independent agreements between a developer and negotiating parties, with or without a formal government role as a facilitator. Advocates of CBAs aim to insert local stakeholders, typically low-income households in the vicinity of development project, directly into the process of recovering the value. They are expected to drive for accountable development by involving communities in formulating, or to arrive at negotiated deal-specific CBAs on the sharing of the value of the resulting development. Wolf-Power (2010) [28] (p. 142) states that, often, the participants in a CBA negotiation are neighborhood groups from the area surrounding the development site, and regularly working in coalition with advocates for affordable housing, environmental quality, and workers' rights. Typically, such negotiations centre on democratic deliberations, participation and in the pursuit of shared social objectives. Overall, deal-specific CBAs are anticipated to remove project uncertainty with local support that produces positive results for the project. However, Wolf-Powers [9] (p. 217) stated that CBA is perhaps the most controversial among the various VC mechanisms and there exists a dual perspective on CBA Musil [27] (p. 842) cited that there were about 30 CBA-based projects in USA as of 2012, and few states have CBA regulations in place. This paper briefly reviewed the findings of the Musil [27] pilot study of various CBAs with particular attention to two CBAs namely; Atlanta Beltline CBA and Gates-Cherokee CBA. The former CBA is about the Atlanta Beltline light rail track around the city, and appropriate area redevelopment along the corridor through creation of a tax allocation district, whose revenue will fund redevelopment area improvements. The latter CBA is about the demolition and redevelopment of the abandoned Gates Rubber factory site into a retail space and housing, with an emphasis on local hiring, affordable housing, and with various other community benefits.

The study highlighted that CBAs are often criticized, as they are negotiated from a limited community perspective because they represent only the views of the CBA coalition and do not reflect the needs of the broader community. Therefore, issues of community identification in CBA negotiation are at the forefront of the shortcomings identified in the study. Further, these studies also revealed the key issues as: constitutional validity of CBAs with respect to issues on process, enforcement, and protection of the agreement; enforcement related binding of contract issues; and CBAs' compliance in the context of existing property laws on land use regulation and planning processes. The Atlanta Beltline CBA is in the context of constructing a 22-mile light rail transit loop around the city of Atlanta, and aimed for financing partly through a 6500-acre tax-allocation district (TAD). The TAD functions by diverting the difference between the baseline taxes and the increased tax increments to repay the municipal bonds issued to finance the Beltline. Though the project created good interest, it was faced with concerns on gentrification and the displacement of residents. While there is no Beltline CBA coalition, the project is being managed in such a way so as to provide enhanced opportunities for public input and a number of community benefits across Beltline projects. Common community benefit principles, included: prevailing wages for workers; a "first source" hiring system to target job opportunities for residents of impacted low income 'Beltline' neighborhoods; and establishment and usage of apprenticeship and pre-apprenticeship programs for workers of impacted Beltline neighborhoods. The City Council approved, with community input and involvement, a number of benefits, including living wages, local hiring and training programs, affordable housing, environmental 
remediation, and funds for community programs. Been [29] (pp. 34-35) alleged, citing Atlantic Yard CBA, that developers forged a CBA with self-interested supporters, while excluding groups pushing for modifications to the project plan, and even claimed revision to a higher subsidy package. Even in the case of Denver's Gates-Cherokee CBA, issues were found to be the differences of opinion on the definition and legal standing of CBAs. This is a clear case of a CBA that ended as a memorandum of understanding with a slate of commitments for community groups, without any legal binding on the defaulters. There is varied success with respect to private CBAs and public brokered CBAs as a facilitator, and it can be further concluded that a CBAs outcome depends on interest-group politics versus democratic public participation approaches [27]. Further, a lack of formal process to negotiate CBAs, lack of structure for public involvement, difficulty of preset timelines for CBA negotiations, and an overall weak structural process for CBA negotiation, are a few key issues of concern for CBA success.

Another such example, popular in Europe in the context of Garden Cities and New Towns, is the strategic land and infrastructure contract (SLICs), to ensure infrastructure delivery through land value capture. The SLIC concept is to secure delivery of infrastructure using land value capture and voluntary land pooling. Typically, SLICs include a contract between land owners or developers, local authorities, and government agencies [11].

Though CBAs and SLICs are driven by a participatory approach in the pursuit of equity and accountable development, they are threatened by the risk of creating local lobby groups and interest-group politics. The critical success factors, which are significant in such approaches, include ensuring deal transparency, community empowerment, accountability, political commitment, inclusive governance, and, most of all, public legitimacy. In this context, VC-based community engagement practices of the North American cities, especially of practices in the context of public transportation in the city of Portland, are worth mentioning. Portland has a history of over 40 years of strong community governance through an established city-wide neighborhood association system and commitment to citizen participation processes at various levels, as part of its pursuance of city-sustainability goals. The Oregon state-level-enabling legal environment, coupled with the Portland local government commitment to broad-based community participation, enabled the implementation of system-development charges through tax-increment financing (TIF), special assessment districts (SADs), and transit impact fees [30]. Portland has used local improvement districts (LIDs) as funding sources to help finance all phases of the Central Streetcar Project. Community participation also played a key role in the success of the LIDs, and Portland is probably among the first cities in USA, since the 1970s that recognized the importance of community engagement and sustainability goals [31]. The city consulted the community, businesses leaders, and interest groups, involving them while developing their Light rail. The city consulted the stakeholders prior to the LID formation, thereby securing their strong support throughout the project. Furthermore, it revised assessments whenever mistakes were made in the assessment calculation process. In the Phase 1 and 2 LIDs, the city averted a potentially contentious political battle by exempting owner-occupied residential properties from paying assessments [31] (p. 92). Furthermore, the city was able to work with the stakeholders to find solutions when problems arose. For example, those living outside the underdeveloped North Macadam urban renewal area (URA) were initially concerned that their funds would be used to subsidize it. The city addressed this concern by creating the North Macadam Overlay, which helped specify the geography of where the URA funds would be expended [31,32]. Behind the successful collaboration of the 
Portland experience there exists strong governance and institutional capacity to garner the support of the community and public agencies at the time of the TIF-district formation. David [32] (pp. 1-2), while appreciating Portland's "coordinated key stakeholder" strategy in their neighborhood community approach, stated that neighborhood leaders successfully persuaded property owners on each leg of the streetcar route that they should support taxes on themselves to pay a major portion of the front-end capital investment. However, this paper suggested that, though Portland has been working on its street car system for the last 30 years, it is only now learning how to fully recoup their operating expenses. Further, Portland has seen unbridled gentrification of the downtown area, and is still struggling with providing needed affordable housing options throughout the city. This was primarily due to the fact that neighborhood associations failed to pay attention to the voice of the under engaged, the people of color or immigrants. This realization led to the initiation of the Community Connect initiative, involving diverse groups, into deliberations.

The case of Portland revealed some conflicts over VC: resident stakeholder groups could oppose SADs, while the business community were generally willing to pay for assessments charged. Therefore, several SADs, formed to fund Portland Streetcar, exempted residential property owners from paying assessments in order to pre-empt opposition from them [31]. Some states in the US required voting on SAD formation, as per local and state legislation. In such cases, extensive community outreach programs or campaigns were required in large residential neighborhoods to educate them on the transit benefits, or simply to exempt them from paying property tax [32]. Different experiences from U.S. cities suggest that the best approach for coordinating stakeholder input will depend on the objectives for the transit corridor, corridor type, local context, and regional conditions [31].

Overall, the key lesson from these experiences is that early engagement of the key stakeholders, involving the local residents, neighborhood organizations, real estate developers, and small business owners, alongside transit agencies and city or county government in the project life cycle, can yield productive collaboration and coalition-building. The importance of high-level political support, proper legislation, and inclusive governance are keys to build trust and make a difference to the success of community engagement. For example Oregon state-enabling legislation, and its authoritative sponsorship of the process and openness to input, bolstered the credibility and effectiveness of community collaborations, negotiations, and recommendations [33,34]. Community outreach, seed money grants, work opportunities, faster implementation timelines, committed leadership, local champions; and deployment of skilled neutral facilitators are critical to sustained collaboration [34].

The PSVC framework presented in this paper is inspired from such community engagement experiences and best practices in the context of emerging cities that are and focused on a strategic VC-perspective.

\subsection{Need for a Participatory VC Stakeholder Engagement Framework for Cities in Developing Countries}

Many cities in developing countries are still at a nascent stage of understanding and in implementing innovative practices like deliberative forms of democracy and VC-based financing, especially in building urban rail transit systems. In India, more particularly, after the 73rd and 74th amendments to the Indian Constitution, the decentralized governance framework has introduced a new dynamic into the overall process of participatory democracy [35]. In 2011, the Government of India 
issued an advisory to cities on exploring monetization of urban land values through innovative financing mechanisms to build urban transit infrastructure projects. Few cities across India have attempted tapping urban land values such as introducing impact fees, higher floor-area-ratio (FAR) sale, toll fees, auction of vacant public properties, betterment charges, and joint development of open areas, in the context of rail transit, BRT, highways development, and town planning schemes. There is little evidence of any broad-based active community engagements beyond administrative consultations or information sharing, while implementing such charges resulted in small, one-time charged tax revenues [13,36,37]. The majority of cities, especially in developing countries, have not yet fully explored the possibilities of a participatory approach to $\mathrm{VC}$ with a strategic planning perspective. Interestingly, there is definitely a drive among them in realizing the advantages of such practices [36]. What is lacking, however, is a keen understanding of VC process-oriented methodology or strategic engagement framework guidance with various planning interventions across the VC life cycle. To bring all stakeholders to the same level of understanding and consensus building regarding the problems and potential solutions for the transit corridor based development requires a significant amount of skills, knowledge sharing, flexibility, empowerment, and time to be spent [37]. This demands facilitated policy development, mediated negotiations, sustained collaboration, and productive stakeholder involvement. This raises many questions and concerns regarding implementation, which include: who are the key stakeholders to engage with, what are the objectives of such engagement, what are the appropriate engagement techniques and models to be used, how to encourage participation and ensure commitments, and how do we monitor the effectiveness of such engagement.

The PSVC process framework proposed in this paper is conceived to address such concerns and is based on the good practices which already exist and are packaged into a focused end to end strategic framework across the VC life cycle from planning to implementation in an urban rail transit context.

\section{VC Process Life Cycle}

Worldwide, many cities have implemented VC-based infrastructure-financing options in a stage wise process, but have differed in the adoption of VC mechanism strategies. These stages can describe the process of the VC-based transit funding project life cycle, from planning to implementation. The entire VC process is classified into six stages: initiation, planning, design, strategize, execution, and operation. The participatory sustainability approach recommends engaging stakeholders across all six stages of the VC process life cycle. These stages are predominantly the same in any VC-based project, however, the key processes followed within each stage may vary slightly. This can be further explained. For example, the first stage is "initiation", which is the conceptualization phase where the possible transit network, alignment options, land use, legislation, and regulation perspectives are considered. Similarly, the second to fourth stages, "planning", "design", and "strategize", include the process of defining and structuring the $\mathrm{VC}$ for the transit project. Indeed, the actual process of VC planning, design, and strategizing kick off during these phases. The last two stages of the VC life cycle, "execute" and "operate", drive the VC implementation and VC operationalization. The key processes of VC, across each stage for any urban rail transit project, are illustrated in Figure 1. 


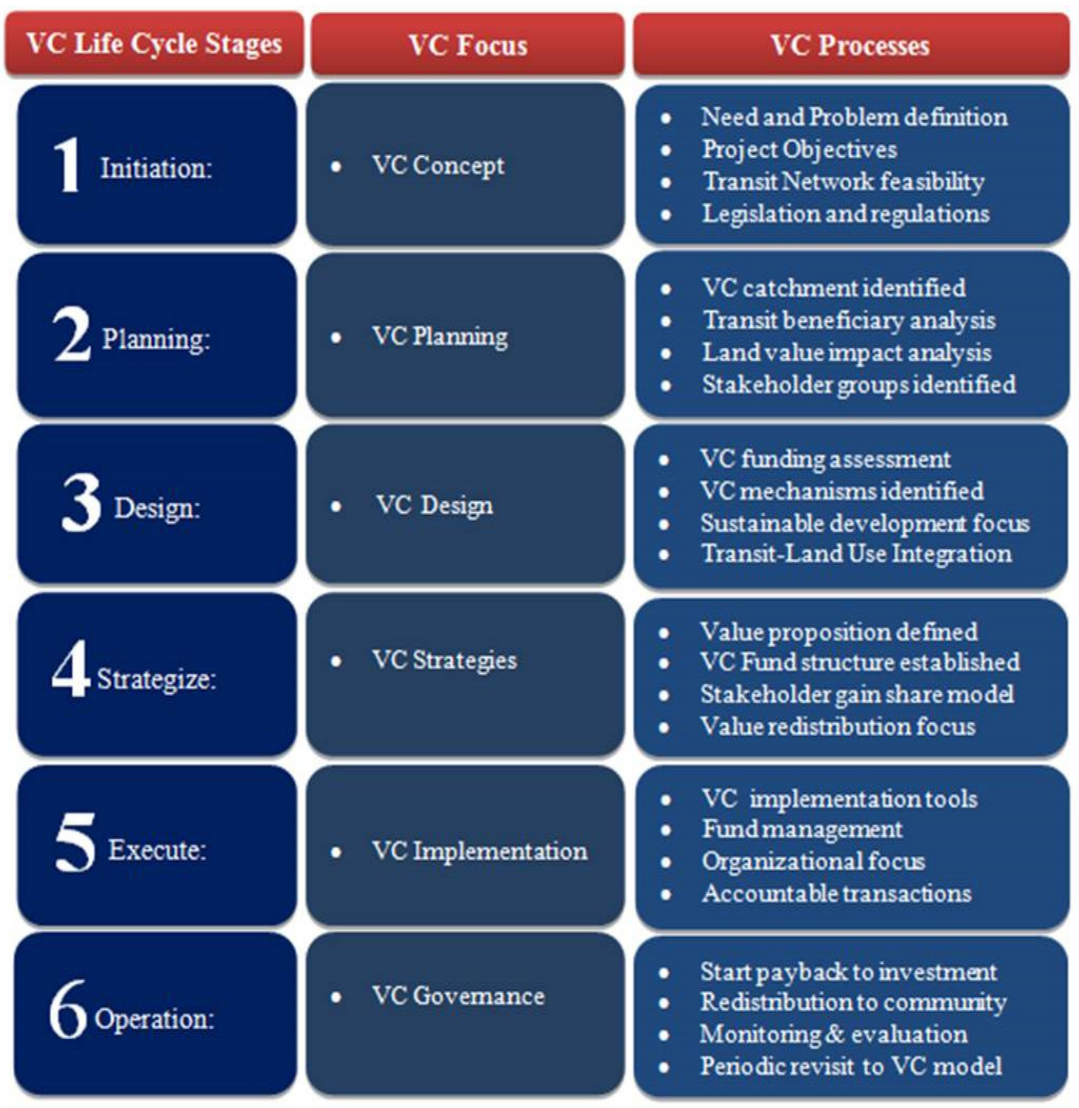

Figure 1. VC stages, key VC focus, and key VC processes across the VC life cycle.

Now the challenge is how to apply the stakeholder engagement strategy across the VC life cycle. The participatory approach to $\mathrm{VC}$ is more like creating and articulating transit impact on land value gain, and sharing the gain, involving all stakeholders in a win-win strategy for the community at large. Such stakeholder engagement shall rightfully begin from the infrastructure-investment planning phase, and jointly identify numerous ways of creating value and, then, to conceptually deliberate the means to capture from such gains. The following section will detail the PSVC framework to enable the stated participatory sustainability approach in a VC-based urban rail transit funding context.

\section{Participatory Strategic Value Capture (PSVC) Framework}

The PSVC framework offers a platform from which to undertake a stakeholder engagement process in VC-based rail transit financing projects. This framework requires the participation of all stakeholder groups at various stages of the VC process life cycle. This means involving stakeholders in all stages of the process, from the initial defining of the $\mathrm{VC}$ process, which is to be used for the operationalization of the project on a continuous basis. The PSVC framework is envisioned to provide a common path to dialogue and deliberation among key stakeholders, mutually acceptable resolutions, community aspirations and needs. This means that when value creation and capturing are facilitated from development proposals that build urban rail transit systems then at the same time they should enable sustainable station neighborhoods. The PSVC driven participatory approach to VC-based project funding is to help improve trust, negotiation, and dialogue between different stakeholders, and 
to build a broader ownership of the VC process with commitment. The key success factors to achieve a successful PSVC-driven stakeholder collaboration include:

- Broad based community participation is enabled

- Effective communication and commitment is created

- Concurrence on shared goals, value created or expected

- Strategic, independent, adaptive and transparent approaches are developed

- Building trust among stakeholders through being inclusive

- Unbiased engagement objectives and plans are set upfront

- Equity in value redistribution is given due importance

- Sustainability goals are incorporated along with transit goals

- Transit station neighborhood aspirations are aligned with the project

- Conflict management processes are set up

- Stakeholder capacities are strengthened to enable adequate engagement

- Compliance with the city priorities, policy framework and legislation is enabled

Thus, the PSVC framework focuses on that designing of processes that facilitates value creation learning, deliberates on value redistribution and promotes joint action to determine agreed multiple VC-based outcomes. These need to simultaneously suit transit funding and also neighborhood revitalization. Essentially this provides a framework and a strategic forum, offering step-by-step guidance to the participatory approach identifying various interventions across the VC life cycle to fund and finance urban rail transit systems, rather than being applied in context for a particular VC tool. The proposed PSVC framework is comprised of a sequential four-step stakeholder engagement model:

Step 1: Identify Stakeholders

Step 2: Set Engagement Objectives

Step 3: Select Engagement Techniques

Step 4: Monitor Engagement Performance

Each of these steps will be described in detail in this section.

\subsection{Step 1: Identify Stakeholders}

Step one involves identifying and classifying the necessary project stakeholders at the onset of the project. The next step is to classify the identified stakeholders into specific groups based on their interests in the project. In a VC-based transit financing project context, we can broadly classify the stakeholders into three major groups: investors, wind-fall beneficiaries, and city community [37,38]. The three major stakeholder groups for an urban rail project, along with the stakeholders that could be included in these groups, and their aspirations, are illustrated in Figure 2.

The first stakeholder group is the "Investor" group. These are the stakeholders who provide the capital or investment in the project. They, along with providing a public good, also require a return on investment. The "Wind-fall Beneficiary" group are those who benefit by the delivery of the project, generally through their proximity to the project, and with urban rail projects, from the increased accessibility, the increased property values, increased rents, agglomeration of new economies, and land use changes, that happened due to the implementation of the rail project. The third group, the 
"Community" group, includes the local community members with direct access to the project, particularly the low-income community groups within the vicinity, and the city tax payer community at large $[11,36]$. Understanding the aspirations and cross-sectorial objectives of these groups provides a solid platform to be able to define the appropriate $\mathrm{VC}$ process to be undertaken.

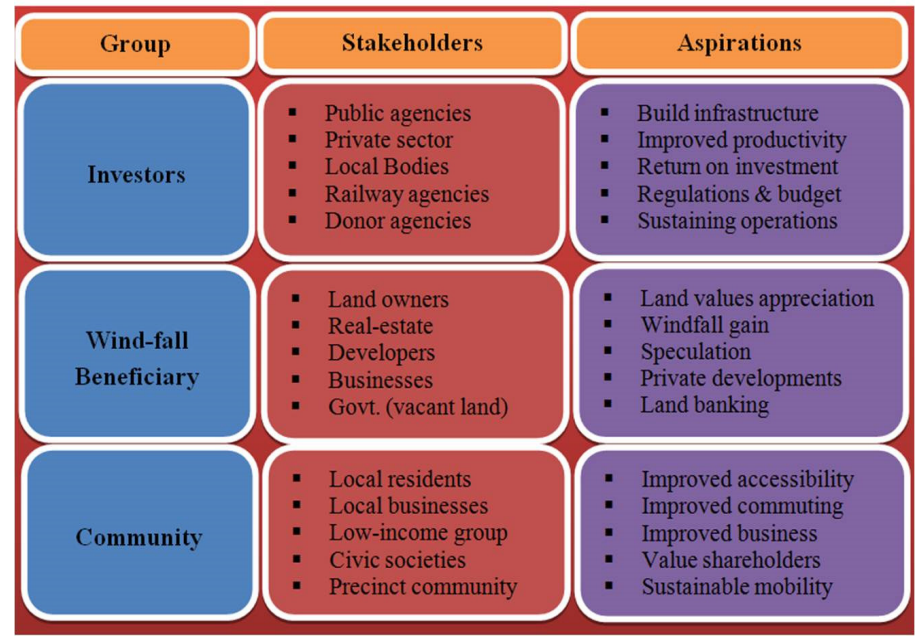

Figure 2. VC-based urban rail financing project stakeholders and their aspirations.

\subsection{Step 2: Set Engagement Objectives}

The second step involves defining the stakeholder engagement interventions and objectives across the VC life cycle as shown in Figure 3.

\begin{tabular}{|c|c|c|}
\hline VC Life Cycle & VC Key Processes & Engagement Objectives \\
\hline $\begin{array}{l}\text { Initiation: } \\
\text { VC Concept }\end{array}$ & $\begin{array}{l}\text { - Need and Problem definition } \\
\text { - Project Objectives } \\
\text { - Transit Network feasibility } \\
\text { - Legislation and regulations }\end{array}$ & $\begin{array}{l}\text { - Information sharing } \\
\text { - Public workshop } \\
\text { - Coed validation } \\
\text { - Consultation }\end{array}$ \\
\hline $\begin{array}{l}\text { 2. Planning: } \\
\text { VC Planning }\end{array}$ & $\begin{array}{l}\text { - VC catchment identified } \\
\text { - Transit beneficiary analysis } \\
\text { - Sand value impact analysis } \\
\text { - Stakeholder groups identified }\end{array}$ & $\begin{array}{l}\text { - Deliberation } \\
\text { - Wilingness to Pay } \\
\text { - Pommitment } \\
\text { Participation }\end{array}$ \\
\hline $\begin{array}{l}\text { Design: } \\
\text { VC Design }\end{array}$ & $\begin{array}{l}\text { - VC funding assessment } \\
\text { - VC mechanisms identified } \\
\text { - Transit-Land Use Integration }\end{array}$ & $\begin{array}{l}\text { - Deliberation } \\
\text { - VC Instruments } \\
\text { - In Incentives } \\
\text { In Steering Group }\end{array}$ \\
\hline $\begin{array}{l}\text { Strategize: } \\
\text { VC Strategies }\end{array}$ & $\begin{array}{l}\text { - Value proposition defined } \\
\text { - VC Fund structure established } \\
\text { - Stakeholder gain share model } \\
\text { - Value redistribution focus }\end{array}$ & $\begin{array}{l}\text { - Deliberation } \\
\text { - Entrusting community } \\
\text { - Recountability } \\
\text { Responsibility }\end{array}$ \\
\hline $\begin{array}{l}\text { Execute: } \\
\text { VC Implementation }\end{array}$ & $\begin{array}{l}\text { - VC implementation tools } \\
\text { - } \text { - Organd management } \\
\text { - Accountable transactions }\end{array}$ & $\begin{array}{l}\text { - Inclusive govemance } \\
\text { - Deliberation } \\
\text { - Engagement } \\
\text { - Transparency }\end{array}$ \\
\hline $\begin{array}{l}\text { Operation: } \\
\text { VC Governance }\end{array}$ & $\begin{array}{l}\text { - Start payback to investment } \\
\text { - Redistribution to community } \\
\text { - Monitoring \& evaluation } \\
\text { - Periodic revisit to VC model }\end{array}$ & $\begin{array}{l}\text { - Deliberation } \\
\text { - Review \& evaluation } \\
\text { - Sustainability focus } \\
\text { - Benefit assessment }\end{array}$ \\
\hline
\end{tabular}

Figure 3. Stakeholder engagement interventions across the VC life cycle. 
The engagement objectives need to be defined across all the six stages of the VC life cycle. The initial stage is more of a conceptual stage. Therefore, the set engagement objectives at this stage could include information sharing, communication of project goals, the elicitation of community views, validation of the problem, and determining the anticipated value addition through consultations. Similarly, stakeholder engagement objectives during the second, third, and fourth phases would involve participation, deliberation, and co-creation from all groups, as identified above, and involves deliberating and agreeing on the various $\mathrm{VC}$ mechanisms to be utilized. The last two stages of the VC life cycle drive the VC implementation and operationalization. During these last two VC stages, the set engagement interests are primarily collaboration, engagement, and empowerment through active participation in project steering groups and governance in order to ensure the set project objectives are achieved.

\subsection{Step 3: Select Engagement Techniques}

The third step facilitates the undertaking of stakeholder engagement by identifying appropriate engagement techniques that could be used across a VC life cycle. Primarily, this step focuses on establishing which engagement techniques might work best in each stage of the VC life cycle. DD techniques cross referenced with VC life cycle and engagement objectives are shown in Figure 4.

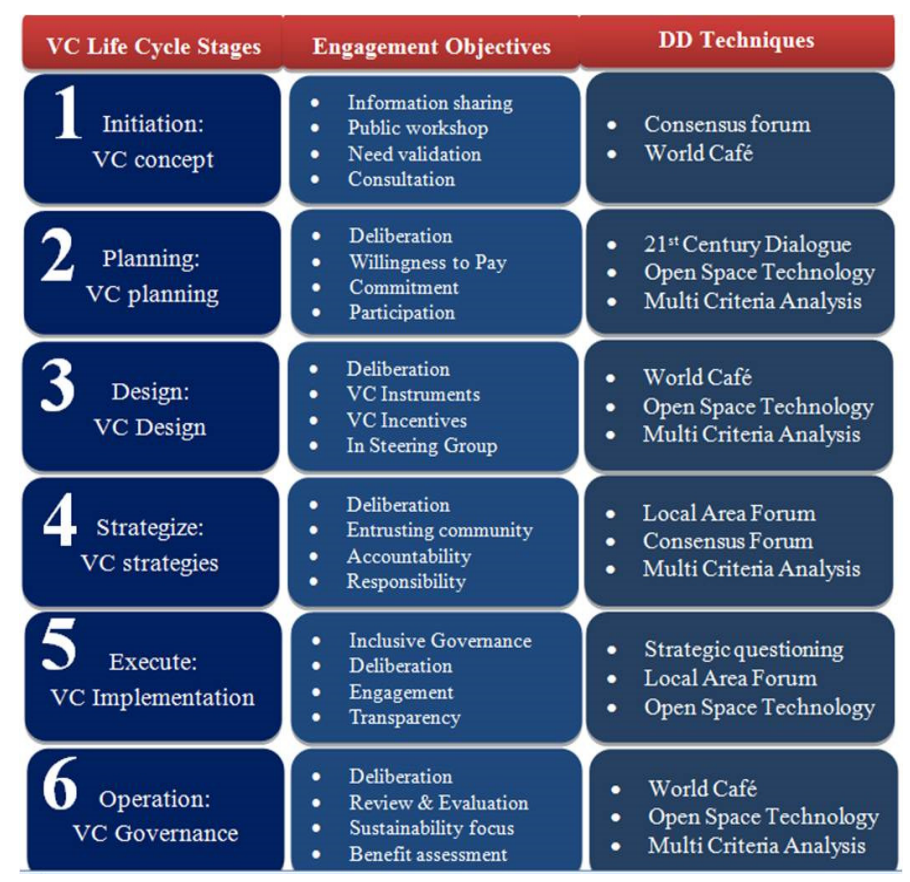

Figure 4. Stakeholder engagement and DD techniques across a VC life cycle.

DD techniques are helpful in enabling and facilitating the participatory sustainability approach. The rationale behind the recommended technique in each stage is more based on the set engagement objective. In the first stage the likely engagement strategy is more on consultations, dialogue and validation of the set project goals. World cafés and consensus forums are the most suitable techniques to facilitate such deliberations. The following stages 2 and 3, require more deliberation, active participation and ideation based engagement interests. Accordingly, the selected DD techniques, such as the 21st Century Dialogue, Open Space Technology and Multi-Criteria Analysis will help in identifying the issues, prioritization, and in achieving more committed participation of the 
stakeholders. Similarly the local area forum-based engagement will bring more of the micro level issues into focus and also solutions to solve any problems. These suggested DD techniques have been proven and will help to facilitate either larger or smaller group deliberations toward achieving a common ground. In addition to the above-suggested list of DD techniques, there is a host of stakeholder engagement techniques, tools, and campaigns, that are available with extensive literature and internet-based data sources. Stakeholder engagement objectives and the deliberation group size are key considerations in choosing an appropriate technique.

\subsection{Step 4: Monitor Engagement Performance}

Step four involves reviewing the stakeholder engagement model undertaken, and occurs after the process has started and is ongoing over the project's life cycle. A periodic review of stakeholder engagement is undertaken, at each stage of the VC life cycle. This helps in understanding the performance of the various stakeholder groups against the set objectives and targets. From time to time it is advisable to have a check point to measure the effectiveness of the engagement performance, and also to evaluate any risk groups or dependent activities. Performance indicators are a set of interpretable, communicable, comparable measures for tracking the engagement effectiveness at any defined engagement level or process. This is, however, project specific. Therefore, at the beginning of the VC process, check points, or stages to measure the performance, need to be identified.

The PSVC framework enables participatory monitoring and evaluation by internally defined indicators that are locally relevant, context specific, or stakeholder processes based on qualitative and quantitative judgment. Quantitative indicators are used to measure the magnitude of the outcome, while qualitative indicators describe the quality of the participation. At the same time, indicators may differ with respect to the aspirations of different stakeholder groups. Therefore, to accommodate such pluralism, a disaggregated model of indicators needs to be developed. Furthermore, the level of engagement and the various stages of the VC life cycle in which engagement is desired would also influence the type of indicator to be applied. Primarily indicators are methods to analyze, monitor, learn, identify risks, and, if required, make course correction changes toward achieving the set engagement objectives. The World Bank-developed participatory monitoring and evaluation (PM\&E) process tool proposes that indicators selected for a particular project need to be valid, relevant, specific, timely, reliable, sensitive, and cost-effective [39].

A suggested list of possible indicators for process participation across the VC life cycle within a PSVC framework is summarized in Figure 5. The suggested indicators list is by no means meant as a model list of indicators to be used, but rather as a guide, as an example of what might be needed in various project practices. Various tools, such as before and after surveys, stakeholder feedback forms or interviews, questionnaire-based responses, opinion surveys, web-enabled feedback inputs, measurable outcomes or commitments, are applied to gather data for the indicators. 


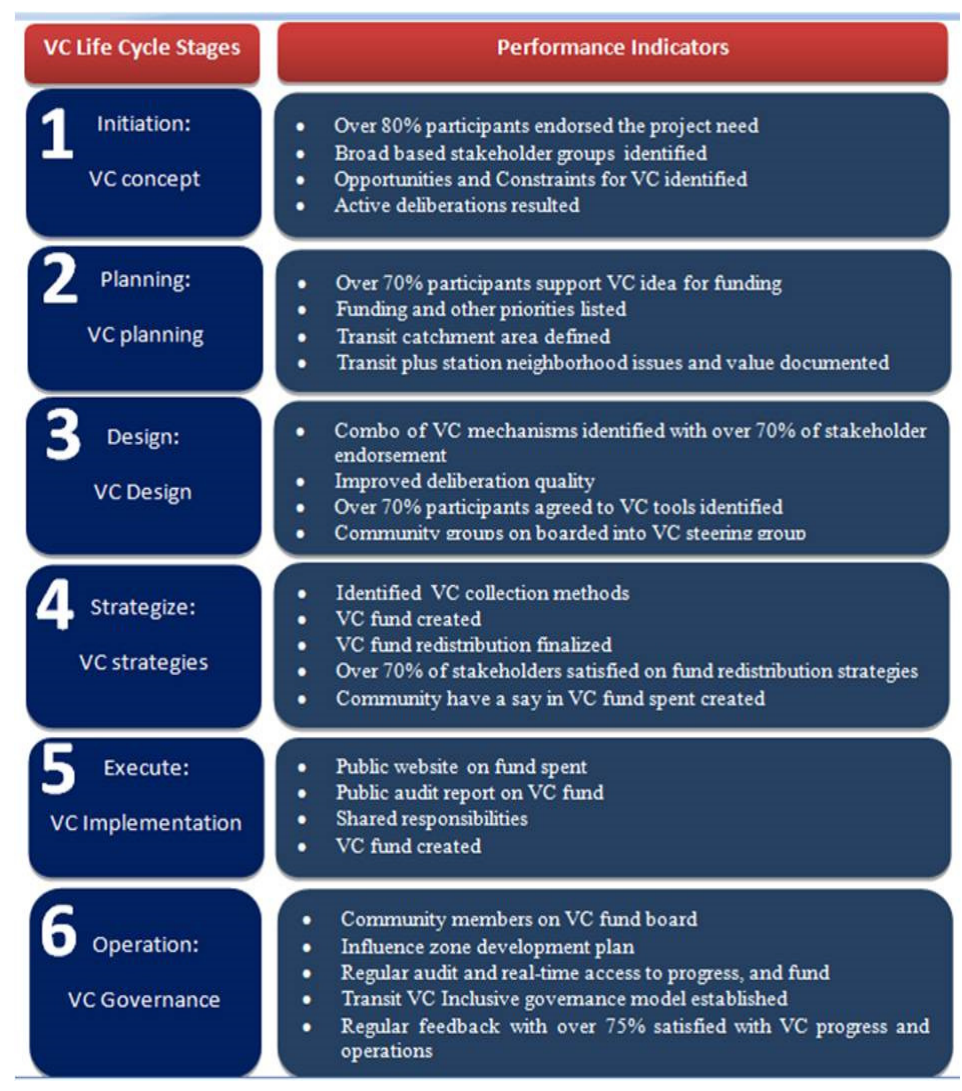

Figure 5. Stakeholder engagement monitoring and indicators across a VC life cycle.

The next section of this paper describes how these PSVC framework steps could be applied in practice, utilizing a case study of the proposed Bangalore suburban rail project.

\section{PSVC Framework Applied to the Proposed Bangalore Suburban Rail Project}

Bangalore city is urbanizing at an unprecedented scale and has a current population of over 8.5 million. The urbanization process has been defined by increasing urban sprawl (though not as low density as in American cities) and the development of a complex transport pattern (increasingly car dependent). This urbanization process presents a formidable commuting challenge today. The Comprehensive Traffic and Transportation Plan for Bangalore recommended the implementation of a suburban rail system, to link Bangalore to surrounding cities within a radius of $50-70 \mathrm{~km}$ in order to help reduce dependence on road-based transportation [25]. Considering the potential benefits of suburban rail services, the State Government of Karnataka has given its in-principle approval for the project, and a Detailed Project Report (DPR) for its implementation has commenced [40]. Currently, the proposed suburban rail plan is to use the existing inter-state rail network of about $370 \mathrm{~km}$ to connect towns, suburbs, and the inner city by introducing capacity and improving the frequency of operations.

Along with the DPR preparations, the Government of Karnataka is also keen to explore alternative innovative financing options to build the suburban rail. To this end, the Directorate of Urban Land Transport (DULT) from the Government of Karnataka State, India, signed a memorandum of understanding with the Curtin University Sustainability Policy (CUSP) Institute, Australia, and Center for infrastructure, sustainable transport and urban planning (CiSTUP) of Indian Institute of Science, 
Bangalore to help facilitate a VC-based funding strategy. According to the VC life cycle described above, the current progress of this suburban rail project can be defined as between the "Initiation" and "Planning" stages. Though, conceptually, the project initiation and feasibility study was completed in 2013, the participatory route through stakeholder engagement has not been initiated thus far.

Therefore, as part of this project, under the auspices of AusAID sponsorship, a two-day stakeholder deliberation workshop on "Bangalore Suburban Rail Project: potentials for innovative financing and planning strategies" was held on 9-10 October 2013, in Bangalore, India. The objective of this workshop was to introduce VC- based innovative financing mechanisms through knowledge-sharing sessions and to conduct deliberation on the feasibility of the application of such $\mathrm{VC}$ concepts in the Bangalore suburban rail project context. The workshop used a participatory sustainability approach to which the PSVC framework was applied in order to demonstrate its use in practice, particularly the applicability of undertaking stakeholder engagement, using appropriate DD techniques. The core question for the deliberation around using VC in the Bangalore Suburban Rail project was identified to be "can we improve understanding and skills around transit oriented design and VC based suburban rail financing through stakeholder engagement using deliberative democracy techniques in Bangalore?" This project has enabled the testing of the application of the PSVC framework. The steps undertaken during this process are described next following the four-step PSVC framework described above, along with detailing the process so far, the outcomes and the way forward for this innovative project.

\subsection{Step 1: Stakeholder Identification}

Following the PSVC framework classification, as the first step we identified the stakeholders that would be involved in this project. They were broadly identified as: state government agencies, railway organizations, and representing the "investor" group; the local station residents and business groups, including slum dweller representative associations residing within a distance of $1 \mathrm{~km}$ from station, and community groups from suburban towns representing the potential "wind-fall beneficiary" groups; and, finally, the community group stakeholders identified as representatives from citizen forums, NGOs, and resident associations. On the first day of the workshop deliberation involved about 80 high-level participants from a wide range of organizations and also community members. The second day involved a smaller group of 26 key stakeholders, to summarize and agree on the next steps. These Day 2 participants were selected in such a way so as to ensure at least one or two representatives from the all identified stakeholder groups participated in the "way forward" discussion. Primarily, Day 1, with greater participation, planned for deliberation, and Day 2 planned to summarize the deliberation into action and agree on a way forward.

\subsection{Step 2: Set Engagement Objectives}

Following the PSVC framework, the project was defined as "post initiation" and in the "planning" stages of the VC life cycle. This provided an opportunity to orchestrate the stakeholder engagement workshop during the second stage "planning" of the Bangalore suburban rail project. This workshop primarily focused on bringing together key stakeholders of the proposed Bangalore suburban rail to deliberate on innovative financing options using VC mechanisms and to determine a way forward that maximizes suburban rail attractiveness, sustainability, viability, and accessibility. The stakeholder 
engagement objectives defined were to encourage deliberation on the identified core questions and understand stakeholder willingness to participate in the VC-based financing process.

Keeping in mind that no prior stakeholder consultations had taken place during the project initiation stage, except for a consultant study on project feasibility, it was decided to include a knowledge-sharing session during the workshop on Day 1. This provided an opportunity to enable all stakeholders to understand land-based VC financing mechanisms and to hear from experts sharing global best practices. This was followed by a core group deliberation, which included validating the $\mathrm{VC}$ concept with respect to its applicability to the proposed Bangalore suburban rail project. The key sub-questions discussed during the focused deliberations were: "how can we make VC work in Bangalore?" and "which one among them will be the most important to make VC work in Bangalore?" The deliberations concluded with a discussion about the constraints and opportunities of the VC process in the Bangalore context.

In the future, if the process was to follow the PSVC framework, a number of deliberation workshops would need to be organized as per the suggested stakeholder interventions across the VC life cycle stages, as presented in Figure 2. These could include stakeholder participation across remaining stages of the life cycle: the "VC design", i.e., to identify the appropriate VC instruments to value assessment, stakeholder willingness to participate, as would be appropriate in the project context. A project steering group with representation from the stakeholder community could help in creating the "roadmap" to strategize the VC process. This would enable stakeholder involvement to move from participation to engagement. The following fourth stage, "VC strategies" would set an agenda for the stakeholder community to jointly structure the VC fund and its redistribution strategies, as identified upfront. Then, in the fifth stage, "VC Implementation", and the last stage, "VC Operationalization", it enables stakeholders to be part of $\mathrm{VC}$ governance through reviewing the progress of the project and evaluation of the $\mathrm{VC}$ process, as measured by the stated engagement interests and commitments.

\subsection{Step 3: Select Engagement Techniques}

This stage is about identifying the appropriate stakeholder engagement techniques, as recommended by PSVC framework, appropriate for the "planning stage" of the VC life cycle. On Day 1, the two main DD techniques deployed were: 21st Century Town Meeting/Dialogue and Multi Criteria Analysis (MCA). On Day 2, the DD technique used was the Open Space Technology technique [40]. Day 1 involved small, facilitated groups, using networked computers linked to an innovative online software platform. This platform is designed to facilitate the finding of common ground and common priorities. For key sub-questions, the responses received were classified in real-time into major themes, with the aid of on-line software, and then themes were reviewed and prioritized by participants with an appropriate score assigned to each using weightages. These themes were ranked using the MCA technique. The participants also deliberated on constraints and opportunities around adopting $\mathrm{VC}$ in the context of the proposed Bangalore suburban rail project.

At the end of the Day 1 deliberations, a "Workshop Outcome Report" detailing the key points from the day, including expert presentations and a complete copy of workshop deliberations, key themes, and prioritization scores was compiled and distributed to each participant. Participants were very excited to receive their report, as shown in Figure 6. This presentation of the report was very important 
to maintain interest and enthusiasm with participants, as it enabled participants to have key outcomes immediately, rather than waiting for a report to be produced a few weeks later, as typically happens in traditional workshops [40]. The workshop on Day 2 used the Open Space Technology technique. On Day 2 about 26 key participants representing all stakeholder groups deliberated on the key outcomes from the previous day, and then identified actions, task-owners, and milestones moving forward.

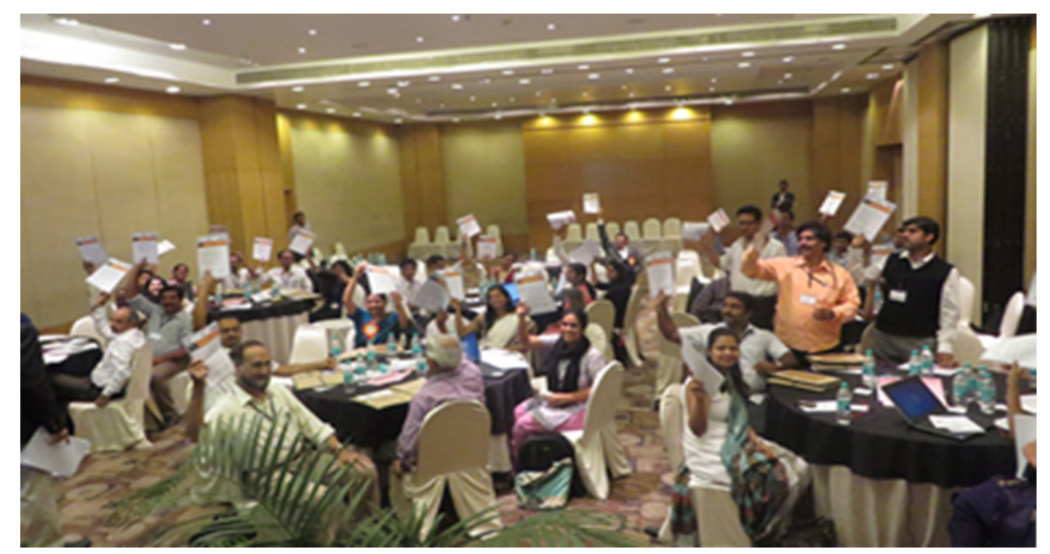

Figure 6. Participants showing the receipt of workshop report in real-time at the end of the Day 1 event.

\subsection{Step 4: Monitor Engagement Performance}

At the end of the event, the workshop results and processes were analyzed and the engagement model used was found to be very positive. This is the first stakeholder workshop in the proposed sub-urban rail project context. As stated earlier, project progress could be defined between the initiation and planning phases. We apply the PSVC framework then the current VC processes are defined between the first and second stages of the VC life cycle. The results are, therefore, primarily evaluated based on the suggested indicators of the PSVC framework, stated in these two stages. Firstly, the workshop was a success in identifying and involving broad based stakeholder groups, including the government, public, private, city community, sub-urban community, local governments, and resident associations from sub-urban station neighborhoods. Secondly, the workshop achieved a consensus on the significance of the sub-urban rail project, and endorsed the urgency of its implementation. The workshop also demonstrated the key learning of VC concepts shared, which were reflected in active stakeholder deliberations. Lastly, all stakeholder groups unanimously agreed that land-based VC financing was appropriate for the project, and also suggested barriers and opportunities in the current system, along with high-level solutions for the alternatives proposed, which was truly a great result within such a short time.

Overall, using the DD process uniquely transformed the role the public normally plays in traditional community consultation, from combative and divisive to cooperative and co-intelligent. As a result of the workshop, being the first of its kind, many more such stakeholder interactions will be planned to achieve the set engagement objectives [40]. This workshop could not yet identify the enablers or community champions to be sought out, which require other channels and one-on-one meetings to ensure a committed participation. In order to understand issues at the network level, many more 
station-neighborhood-based deliberations need to be organized to finalize the plans. Although the workshop discussed the sub-urban rail network influence zone to be within a $1 \mathrm{~km}$ radius from the metro rail, opinions may differ in the sub-urban areas. This again underscores the need to organize sub-urban-based micro-level deliberations at a later stage. Lack of transit funding and other sustainable transportation planning issues were deliberated in the workshop, but require more such deliberations to finalize the priorities list. The identified high priority issues, such as lack of coordination between multiple agencies involved, highlight the fact that transit and development are still functioning in silos and are large challenges for VC-based participatory transit governance.

As this was the first attempt to bring all stakeholders on to a single platform, the performance indicators were not developed on a collaborative basis. In the future, based on the current learning, such targets and expectations can be collaboratively decided in advance of such deliberations. The authors recommend that performance indicators should be classified into macro-level and micro-level targets to measure the outcomes, and identify the need to plan future deliberations or campaigns to achieve the set objectives. This evaluation, therefore, can conclude the event as a $100 \%$ achievement, as far as broader macro-level objectives of information sharing, project significance, willingness to participate in the VC process and its applicability, are concerned. In conclusion, this evaluation also recommends a series of such deliberations and campaigns in the future, during the project planning phase, to further identify stakeholder champions, station-level or network level priorities, and to more clearly seek station community goals and unique sub-urban area concerns that impact on the value proposition.

\subsection{Discussion}

The deliberation process around the potential of $\mathrm{VC}$ in Bangalore enabled real discussions across a variety of stakeholders, enabled potential oppositions or tensions to be considered, and a variety of viewpoints to be expressed, debated, and then a common understanding to be developed. For example, stakeholders deliberated and discussed, in smaller groups, potential "constraints and opportunities" to utilizing the $\mathrm{VC}$ process in the Bangalore suburban rail project. The group responses were classified in real-time, with the aid of on-line software, into major themes coming from the entire group. These themes were then prioritized. This technique facilitated iteration, enabling the group to continue discussing until a clear idea or action was identified. Indeed, using the MCA technique with weightings to prioritize the themes, helped to define the whole VC process. From the example above, "constraints and opportunities", the major constraint to utilizing VC in the Bangalore suburban rail project was collectively decided to be that: "There is a lack of collaboration, coordination and capacity between and within agencies, with many conflicting interests. Better coordination is essential", and for opportunities, "VC schemes are popular and offer opportunities for involvement with various stakeholders (private sector, developers, land owners and citizens)" [40]. From this, the next steps can be determined and potential opposition can be aired and deliberated on so that a common understanding is developed and formalized through the workshop outcomes report. In this example, this was undertaken very quickly, in two days, using the framework driven approach described above. Overall stakeholder acceptance of the VC process and the feasibility of the project was agreed on. If the participatory sustainability approach had not been undertaken, then developing this common 
understanding may have taken a much longer time, using more common stakeholder engagement processes, or not happened at all.

Moreover, the PSVC framework-driven stakeholder engagement approach, not only provided a platform for facilitating the development of a common ground, but also provided a source for cross-pollination of new knowledge and new ideas to VC value assessment. For example, when the beneficiary group deliberated in smaller groups, they deliberated on what the possible equity implications were and also the possible negativities they would face during the project construction phase. In reality, this group, due to their proximity to the project site, does experience much greater anxiety, interruptions to their businesses, traffic chaos, and other pollution-related negatives during the project construction period. Thus, the discussion occurred regarding how this negative externality could be compensated for from the increased land value gained later in the process, how this could be designed into the appropriate VC mechanism, and how this could be used to determine the value assessment criteria in VC design at a later stage. These ideas and discussions may never have occurred without this deliberation. Additionally, the group deliberated on commuter demand from the affordability criteria rather than proximity-based traditional capacity estimates, which may often lead to exaggerated demand. This is an important input for suburban rail capacity planning as the beneficiary community mainly provides the catchment capacity and also source for fare box revenues at a later stage. Lastly, participants identified support infrastructure requirements, such as bicycle paths, foot paths, auto-rickshaw parking, vehicle parking and smart fare systems, as essential investments and critical to making the station accessible and suburban rail an attractive commuter choice. This enhanced the scope of VC financing, to not only cover the cost of the rail infrastructure provision, but also to include the cost of providing the support infrastructures around the stations as well. Often, these support infrastructure investments are ignored during VC redistribution by rail authorities, as most of such support infrastructures need to be provided by other government agencies. The above are a few examples that highlight the significant value of the deployment of the PSVC framework-driven participatory sustainability approach to positively contribute in enhancing the planning and design of the VC process. The received inputs from the stakeholders were very useful for this planning stage, and will greatly help the Bangalore suburban rail VC design stage. As part of the next steps, post-DPR study completion, it was agreed to initiate the value assessment along the identified suburban rail corridors to identify potential VC mechanisms and strategies to generate revenues.

Overall, participants found several meaningful opportunities to engage in public deliberation, policy development, and decision-making during the workshop. Though it was a successful deliberation within the given constraints of time, stakeholder participation has not yet translated into engagement levels. As the project is still in a planning stage, as a work-in-progress, further stakeholder engagement needs to be continued throughout the life cycle of the VC process. Another important immediate future step is to identify key stakeholders to be a project steering group. Thus, the PSVC framework, applied to the proposed Bangalore suburban rail project in India, has demonstrated the importance of stakeholder engagement in order to enable sustainable development community goals and to review VC strategies from a win-win perspective. 


\section{Conclusions}

VC integrates the land use and transit system to enable an alternate revenue source, which is traditionally ignored due to a flawed revenue focus. However using $\mathrm{VC}$ as a pure revenue raiser, instead of incorporating a participatory approach, is likely to lead to inequitable results. A participatory approach is, thus, an essential element of all VC planning and implementation processes. Stakeholder participation enables concerned parties to understand each other's requirements and limitations, and allows them to work together to reach solutions in a consensus. To this end, the PSVC framework described in this paper provides a unique attempt to enable stakeholder participation in the VC process, and also enable stakeholder participation to strengthen the outcomes of the VC process. The PSVC framework utilizes deliberative democracy stakeholder engagement techniques. These enable each person to meaningfully participate. The PSVC framework is described and tested in the Bangalore Suburban Rail case study. The framework has the potential to provide an important step forward in mobilizing stakeholder support to the innovative financing option of $\mathrm{VC}$, as well as potentially enabling the VC process to explore its true potential. The results suggest that the PSVC framework provides a powerful tool to visualize the value of the project from the point of view of all stakeholders, and also enables increased acceptance and understanding of the project. The PSVC framework also enables the minimization of risks through the early involvement of the stakeholder groups (investors, beneficiaries, and the community). Furthermore, the PSVC framework has the potential to be applied to stakeholder engagement in any VC-based transit-financing project globally, and could be extended to other forms of $\mathrm{VC}$-based urban infrastructure investment by modifying the objectives and the stakeholder groups to reflect the context of the project.

In conclusion, stakeholder-driven VC approaches can shape and reshape any transit-oriented development in compliance with sustainable development goals, including community aspirations with well-defined value creation and value redistribution strategies upfront.

\section{Acknowledgments}

The authors gratefully acknowledge the support provided by the Directorate of Urban Land Transport (DULT) of State Government of Karnataka, India, and CiSTUP, Indian Institute of Science in jointly organizing the Bangalore suburban rail workshop. The authors also would like to thank AusAid, PATREC, and Curtin University for research grants. The authors would like to extend sincere thanks to Janette Hartz-Karp of Curtin University, Australia, for her expert training inputs on participatory sustainability and deliberative democracy approaches, and for her leadership in successfully conducting the Bangalore workshop in India. The authors would like to thank the Editor and anonymous reviewers of the 4th World Sustainability Forum Conference and Sustainability for their guided inputs and publication as part of WSF4, 2014: e-conference proceedings.

\section{Author Contributions}

The paper represents an effort from all three authors. Satya Sai Kumar Jillella drafted this manuscript, established the research paper design, paper methodology, policy analysis, and preparation of figures. Annie Matan supervised, and assisted with the editing, and co-authorship of manuscript. 
Peter Newman supervised analysis, and guided with editing and co-authorship of manuscript. All authors have read and approved the final manuscript.

\section{Conflicts of Interest}

The authors declare no conflict of interest.

\section{References}

1. Newman, P.; Kenworthy, J. Sustainability and Cities Overcoming Automobile Dependence, 1st ed.; Island Press: Washington, DC, USA, 1999; pp. 116-118.

2. Newman, P.; Glazebrook, G.; Kenworthy, J. Peak Car Use and the Rise of Global Rail: Why this is happening and what it means for large and small cities. JTTs 2013, 3, 272-287.

3. Cervero, R.; Duncan, M. Rail's Added Value. Urban Land. 2002, 6, 77-84.

4. Cervero, R. Rail Transit and Joint Development: Land Market Impacts in Washington, DC and Atlanta. J. Am. Plann. Assoc. 1994, 60, 83-94.

5. Smith, J.J.; Gihring, T.A. Financing Transit Systems through Value Capture: An Annotated Bibliography. Am. J. Ecol. Sociol. 2006, 65, 751-786.

6. William, B.H. Value Capture as a Policy Tool in Transportation Economics: An Exploration in Public Finance in the Tradition of Henry George. Am. J. Econ. Sociol. 2001, 60, 195-228.

7. Medda, F.R. Land value capture finance for transport accessibility: A review. J Transp. Geogr. 2012, 25, 154-161.

8. Smolka, M.O. Implementing Value Capture in Latin America: Policies and Tools for Urban Development, a Policy Focus Report; The Lincoln Institute of Land Policy: Cambridge, MA, USA, 2013.

9. Wolf-Powers, L. Community Benefits Agreements in a Value Capture Context. In Value Capture and Land Policies; Ingram, G.K., Hong, Y., Eds.; Lincoln Institute of Land Policy: Cambridge, MA, USA, 2012; pp. 217-232.

10. Gross, J. CBAs: Definitions, values, and legal enforceability. Int. J. Afford. Hous. Comm. Dev. Law. 2008, 17, 36-58.

11. Walker, J. Land Value Capture and Infrastructure Delivery through SLICs. In T\&CP Tomorrow Series Paper 13; TCPA: London, UK, 2012.

12. Smolka, M.O. A New Look at Value Capture in Latin America. J. Land Lines 2012, 243, 10-15.

13. Jillella, S.S.K. Unlocking land values in financing urban infrastructure. In CiSTUP News Letter, Volume 3; Indian Institute of Science: Bangalore, India, 2012; pp. 14-15.

14. Smolka, M.O.; Iracheta, A. Mobilizing Land Value Increments to Provide Serviced Land for the Poor; Lincoln Institute of Land Policy: Cambridge, MA, USA, 1999.

15. Scheurer, J.; Newman, P.; Kenworthy, J.; Gallagher, T. Can Rail Pay? Light Rail Transit and Urban Redevelopment with Value Capture Funding and Joint Development Mechanisms; Institute for Science and Technology Policy: Murdoch University, Perth, Australia, 2000. 
16. OECD. Citizens as Partners: OECD Handbook on Information, Consultation and Public Participation in Policymaking; Organization for Economic Cooperation and Development (OECD): Paris, France, 2001. Available online: http://internationalbudget.org/wp-content/ uploads/Citizens-as-Partners-OECD-Handbook.pdf (accessed on 8 September 2014).

17. Holmes, B. Citizens' Engagement in Policymaking and the Design of Public Services; Australian Parliamentary Library: Canberra, Australia, 2011.

18. OECD. Promise and Problems of E-Democracy; Organization for Economic Cooperation and Development (OECD): Paris, France, 2003. Available online: http://www.oecd.org/governance/ public-innovation/35176328.pdf (accessed on 10 September 2014).

19. OECD. Focus on Citizens: Public Engagement for Better Policy and Services. 2009. Available online: http://www.oecd.org/dataoecd/20/3/42658029.pdf (accessed on 8 January 2015).

20. Ramanathan R. A note on the use of the analytic hierarchy process for environmental impact assessment, J. Environ. Manag. 2001, 63, 27-35.

21. Kenneth, M.A.; Andrew, C. Stakeholder engagement: A mechanism for sustainable aviation. Corp. Soc. Responsib. Environ. Manag. 2006, 13, 245-260.

22. Bolton Council. Involving Our Communities: Bolton's Community Engagement and Tool Kit. 2007. Available online: http://www.bolton.gov.uk/sites/DocumentCentre/Documents/Community EngagementAndConsultationToolkit.doc (accessed on 10 May 2015).

23. Hartz-Karp, J. How and why deliberative democracy enables co-intelligence and brings wisdom to governance. J. Public Deliber. 2007, 3, 1-9.

24. Carolyn, J.L.; Lars, H.T. Public Deliberation: A Manager's Guide to Citizen Engagement. IBM Center for the Business of Government, 2006. Available online: http://www.businessof government.org/report/public-deliberation-managers-guide-citizen-engagement (accessed on 20 June 2015).

25. Hartz-Karp, J. Deliberative Democracy: Techniques that Create Opportunities for Joint Decision-making. In Participatory Sustainability (302475) Unit Information and Learning Guide; Curtin University of Technology: Perth, Australia, 2013; pp. 45-119.

26. Margaret. G.; Hartz-Karp, J. The Role of Deliberative Collaborative Governance in Achieving Sustainable Cities. J. Sustain. 2013, 5, 2343-2366.

27. Musil, T.A. The sleeping giant: Community benefit agreements and urban development. J. Urban Law. 2012, 44, 827-852. Available online: http://ir.stthomas.edu/ocbfincpub/18 (accessed on 20 April 2015).

28. Wolf-Powers, L. Community Benefits Agreements and Local Government: A review of recent evidence. J. Am. Plan. Assoc. 2010, 762, 141-159.

29. Been, V. Community benefits agreements: A new local government tool or another variation on the exactions theme? Univ. Chicago Law Rev. 2010, 771, 5-35.

30. Christopher, D.H.; Mark, R.F. The North American Light Rail Experiences: Insights for Hamilton; McMaster University: Hamilton, ON, Canada, 2012. Available online: http://mitl.mcmaster. ca/documents/MITL_LRT_August.pdf (accessed on 20 June 2015). 
31. Mathur, S.; Smith, A. A Decision-support Framework for Using Value Capture to Fund Public Transit: Lessons from Project-specific Analyses. 2012. Available online: http://transweb.sjsu.edu/ $\mathrm{PDF} /$ research/1004-decision-support-framework-value-capture-public-transit-funding.pdf (accessed on 2 May 2015).

32. David, M. Portland streetcar brings economic development. 2014 Available online: http://www.cincinnati.com/story/opinion/contributors/2014/03/26/portland-cincinnati-streetcardavid-mann/6930051/ (accessed on 20 May 2015).

33. Paul, K.S. Financing the Airport Light Rail Line in Portland, Oregon: A Case study of public-private partnership. J. Struct. Financ. 2001, 7, 54-67.

34. Oregon Metro. Public Engagement Guide: Final Adoption Draft. 2013. Available online: http://www.oregonmetro.gov/sites/default/files/final_draft_public_engagement_guide_112113.pdf (accessed on 8 May 2015).

35. Ministry of Urban Development; National Urban Transport Policy (NUTP); Government of India. National Urban Transport Policy. 2006. Available online: http://moud.gov.in/sites/upload_files/ moud/files/pdf/TransportPolicy.pdf (accessed on 20 June 2015).

36. Cervero, R. Linking Urban Transport and Land use in Developing Countries. J. Trans. Land. 2013, 6, 7-24.

37. Suzuki, H.; Luchi, K.; Cervero, R. Transforming Cities with Transit: Transit and Land-Use Integration for Sustainable Urban Development; The World Bank: Washington, DC, USA, 2013.

38. McIntosh, J.; Newman, P.; Crane, T.; Mouritz, M. Alternative Funding Mechanisms for Public Transport in Perth: The Potential Role of Value Capture, Discussion Paper; Curtin University Sustainability Policy Institute: Perth, Australia, 2011.

39. Larson, S.; Williams, L.J. Monitoring the Success of Stakeholder Management: Literature Review. In People, Communities, and Economies of the Lake Eyre Basin; Mesham, T.G., Ed.; Alice Springs: Canberra, Australia, 2009; pp. 251-298.

40. Newman, P.; Matan, A. Report on Stemming Car Dependency and Improving Transport Options in Indian Cities; Technical report of AusAID Public Sector Linkage Program Project (65080); Curtin University Sustainable Policy (CUSP) Institute: Perth, Australia, 2013.

(C) 2015 by the authors; licensee MDPI, Basel, Switzerland. This article is an open access article distributed under the terms and conditions of the Creative Commons Attribution license (http://creativecommons.org/licenses/by/4.0/). 